\title{
Implementation of population-level screening for frailty among patients admitted to adult intensive care in Alberta, Canada
}

\section{Mise en ouvre d'un outil de dépistage de la fragilité à l'échelle de la population parmi les patients admis aux soins intensifs pour adultes en Alberta, Canada}

\author{
Carmel L. Montgomery, RN, MN • Danny J. Zuege, MD, MSc • Darryl B. Rolfson, MD • \\ Dawn Opgenorth, RN • Darren Hudson, MD • Henry T. Stelfox, MD, PhD • \\ Sean M. Bagshaw, MD, MSc
}

Received: 11 February 2019/Revised: 20 March 2019/Accepted: 8 April 2019/Published online: 29 May 2019

(C) Canadian Anesthesiologists' Society 2019

\begin{abstract}
Purpose A substantial proportion of patients admitted to intensive care units (ICUs) are frail; however, the epidemiology of frailty has not been explored at a population-level. Following implementation of a validated frailty measure into a provincial ICU clinical information system, we describe the population-based
\end{abstract}

Electronic supplementary material The online version of this article (https://doi.org/10.1007/s12630-019-01414-8) contains supplementary material, which is available to authorized users.

C. L. Montgomery, RN, MN · D. Opgenorth, RN

Department of Critical Care Medicine, Faculty of Medicine and Dentistry and School of Public Health, University of Alberta, 2124E Clinical Sciences Building, 8440-112 St NW, Edmonton, AB T6G 2B7, Canada

D. J. Zuege, MD, MSc

Department of Critical Care Medicine, Cumming School of Medicine, University of Calgary and Alberta Health Services,

Calgary, AB, Canada

eCritical Alberta, Alberta Health Services, Calgary, AB, Canada

D. B. Rolfson, MD

Division of Geriatric Medicine, Department of Medicine, Faculty of Medicine and Dentistry, University of Alberta,

Edmonton, AB, Canada

D. Hudson, MD

Department of Critical Care Medicine, Faculty of Medicine and Dentistry and School of Public Health, University of Alberta, 2124E Clinical Sciences Building, 8440-112 St NW, Edmonton, AB T6G 2B7, Canada prevalence and outcomes of frailty in patients admitted to ICUs.

Methods Retrospective cohort study of adult admissions to 17 ICUs. Data were captured using eCritical Alberta. A Clinical Frailty Scale (CFS) score assigned at ICU admission was used to define the exposure (CFS score $\geq$ 5). Primary outcome was hospital mortality. Secondary outcomes were ICU and hospital stay, and receipt of organ support.

eCritical Alberta, Alberta Health Services, Calgary, AB, Canada

H. T. Stelfox, MD, PhD

Department of Critical Care Medicine, Cumming School of Medicine, University of Calgary and Alberta Health Services, Calgary, AB, Canada

Department of Community Health Sciences, Cumming School of Medicine, University of Calgary, Calgary, AB, Canada

S. M. Bagshaw, MD, MSc ( $\square)$

Department of Critical Care Medicine, Faculty of Medicine and Dentistry and School of Public Health, University of Alberta, 2124E Clinical Sciences Building, 8440-112 St NW, Edmonton, AB T6G 2B7, Canada

e-mail: bagshaw@ualberta.ca

Critical Care Strategic Clinical Network, Alberta Health Services, Edmonton, AB, Canada 
Results Fifteen thousand two hundred and thirty-eight patients (81\%) were assigned a CFS score at ICU admission. Of these, $28 \%$ (95\% confidence interval [CI], 27 to 28) were frail. Prevalence of frailty was 9-43\% across ICUs. Frail patients were older [mean (standard deviation) 63 (15) vs 56 (17) yr; $P<0.001]$, more likely to be male (54\% vs $46 \%$ female; $P<0.001)$, and had higher APACHE II scores [22 (8) vs 17 (8); P $<0.001]$ compared with non-frail patients. Frail patients received less mechanical ventilation (62\% vs 68\%; $P<0.001)$ and vasoactive therapy (24\% vs 57\%; $P<0.001)$, but more non-invasive ventilation (22\% vs 9\%; $P<0.001)$. Frail patients had higher hospital mortality (23\% vs 9\%; adjusted odds ratio, $1.80 ; 95 \%$ CI, 1.64 to 2.05, along with longer ICU stay (median [interquartile range] 4 [2-8] vs 3 [2-6] days; $P<0.001)$, and longer hospital stay (16 [8-36] vs 10 [5-20] days; $P<0.001)$ compared with nonfrail patients.

Conclusion $A$ validated measure of frailty can be implemented at the population level in ICU. Frailty is common in ICU patients and has implications for health service use and clinical outcomes.

\section{Résumé}

Objectif Une importante proportion de patients admis dans les unités de soins intensifs (USI) est fragile; toutefois, l'épidémiologie de la fragilité n'a jamais été explorée à l'échelle d'une population. Suite à la mise en cuvre d'un outil de mesure de la fragilité validé dans un système d'information clinique des USI provinciales, nous décrivons, à l'échelle de la population, la prévalence et les conséquences cliniques de la fragilité chez les patients admis dans les USI.

Méthode Nous avons réalisé une étude de cohorte rétrospective des admissions d'adultes dans 17 USI. Les données ont été saisies à l'aide du programme eCritical Alberta. Un score sur une échelle de fragilité clinique (Clinical Frailty Scale (CFS)) attribué lors de l'admission à l'USI a été utilisé pour déterminer l'exposition (score $C F S \geq 5$ ). Le critère d'évaluation principal était la mortalité hospitalière. Les critères d'évaluation secondaires étaient la durée de séjour à l'USI et à l'hôpital, ainsi que le recours à des traitements de support des fonctions vitales.

Résultats Au total, 15238 patients (81\%) ont reçu un score CFS lors de leur admission à l'USI. Parmi ceux-ci, $28 \%$ (intervalle de confiance [IC] 95\%, 27 à 28), étaient fragiles. La prévalence de la fragilité allait de 9 à $43 \%$ dans les USI. Les patients fragiles étaient plus âgés [moyenne (écart type) 63 (15) vs 56 (17) ans; $P<0,001$ ], plus souvent de sexe masculin (54\% d'hommes vs $46 \%$ de femmes; $P<0,001)$ et avaient des scores APACHE II plus élevés [22 (8) vs 17 (8); $P<0,001]$ par rapport aux patients non fragiles. Les patients fragiles ont reçu moins de ventilation mécanique (62\% vs $68 \% ; P<0,001)$ et de support vasoactif $(24 \%$ vs $57 \% ; P<0,001)$, mais davantage de ventilation non invasive (22\% vs $9 \%$; $P<$ 0,001). La mortalité hospitalière était plus élevée (23\% vs $9 \%$; rapport de cotes ajusté, 1,80; IC $95 \%, 1,64$ à 2,05), et la durée de séjour à l'USI était plus longue ([écart interquartile] médian 4 [2-8] vs 3 [2-6] jours; $P<0,001$ ), tout comme la durée de séjour à l'hôpital (16 [8-36] vs 10 [5-20] jours; $P<0,001)$ chez les patients fragiles par rapport aux patients non fragiles.

Conclusion Une mesure validée de la fragilité peut être mise en auvre à l'échelle de la population à l'USI. La fragilité est fréquente chez les patients de l'USI et a un impact sur l'utilisation des services de santé et les pronostics cliniques.

The general health status and functional trajectory of patients prior to an episode of critical illness and intensive care unit (ICU) admission are increasingly recognized as important determinants of the complexity and duration of organ support and outcome. ${ }^{1-4}$ Observational studies estimate one-third of critically ill patients are frail. ${ }^{5-7}$ The prevalence of frailty appears greatest among older patients $^{8,9}$; however, this is not insignificant among younger patients. ${ }^{10}$

Frailty has consistently shown heightened risk for worse short- and long-term outcomes and greater use of health services. ${ }^{5-7,11}$ As such, an understanding of baseline frailty status during critical illness provides additional context on survivorship expectations for patients, families, and healthcare professionals, especially when making decisions on the intensity and/or duration of support provided in ICU settings. ${ }^{12}$

The Canadian healthcare system is confronted with a growing burden of persons living with frailty. There have been widespread recommendations to integrate measures of frailty into clinical practice and across the healthcare spectrum, including in ICU settings. ${ }^{13}$ Recently, we implemented the routine capture of a validated frailty measure into a provincial ICU-specific bedside electronic health record (EHR). ${ }^{14}$ Herein, we describe the populationlevel epidemiology of frailty among critically ill patients across all adult ICUs in the province of Alberta.

\section{Methods}

This study was approved by the Research Ethics Board at the University of Alberta, Edmonton (File \# Pro00056591) 
and the University of Calgary Conjoint Health Research Ethics Board, University of Calgary, Calgary (File \# REB15-1728). Need for written informed consent was waived. This study follows the recommended reporting guidelines outlined in the STROBE statement. ${ }^{15}$

Design, setting, and population

This was a retrospective multicentre population-based cohort study. All adult patients (aged $\geq 18 \mathrm{yr}$ ) admitted to all 17 ICUs in Alberta, Canada between January 1, 2016 and June 30, 2017 were eligible for inclusion in the study. These ICUs included 14 mixed medical/surgical units; two cardiovascular surgical ICUs, and one neurosciences ICU. Study ICUs are in seven cities: Edmonton (seven units), Calgary (five units), Red Deer (one unit), Lethbridge (one unit), Grand Prairie (one unit), Medicine Hat (one unit), and Fort McMurray (one unit). Of these, five are classified as academic, two as tertiary, and ten as community/ regional ICUs (eTable 1, available as Electronic Supplementary Material [ESM]). All ICUs were staffed by board-certified intensivists, generally had in-house coverage by clinical associates or resident trainees, and had availability of after-hours intensivist coverage.

\section{Data sources}

The primary data source was eCritical Alberta, which includes a bedside clinical information system (eCritical MetaVision $^{T M}$, iMDsoft, Boston, MA, USA) and a data warehouse and clinical analytics system (eCritical TRACER). eCritical has been implemented in all ICUs across Alberta since 2012 and serves as a key tool to support best practice in critical care medicine (Alberta Health Services, 2012, eCritical Alberta). ${ }^{14}$ eCritical provides for full electronic interdisciplinary clinical documentation and collation of demographic, diagnostic/case-mix (i.e., comorbidities, diagnostic classification, surgical status), illness severity (i.e., Acute Physiology and Chronic Health Evaluation [APACHE] II and IV scores, and Sequential Organ Failure Assessment [SOFA] scores), laboratory and intervention data (i.e., use of invasive/non-invasive ventilation, vasoactive therapy, and renal replacement therapy [RRT]) utilizing standardized documentation and data definitions. Data are directly entered into eCritical MetaVision ${ }^{T M}$, using forms with discreet data elements and decision support to guide proper documentation and are directly downloaded from medical devices or other systems (i.e., laboratory, admission-discharge transfer). The eCritical Program includes a comprehensive quality assurance process to track and remediate completion of important data elements (i.e., the Physician Admission Form, which includes diagnosis and the Clinical Frailty Scale [CFS] score). Data from eCritical MetaVision ${ }^{T M}$ are imported unaltered into eCritical TRACER using an extract-transform-load tool (Informatica, Redwood City, California). eCritical TRACER provides a reporting and data-extraction capability that supports research, education, planning, and decision-making by providing data and reports from a comprehensive repository of patient-specific ICU clinical information. ${ }^{14}$ The eCritical TRACER repository is housed within Alberta Health Services (AHS) and is governed by a provincial executive group that oversees its rigorous data quality assurance and audit. ${ }^{14}$ eCritical TRACER has previously been used to support health services and outcomes research. ${ }^{16-19}$

\section{Provincial implementation of the CFS into eCritical}

Prior to implementation, healthcare practitioners working in adult Alberta ICUs, particularly physicians, were prepared with a multi-faceted education strategy that focused on providing a rationale for CFS implementation, an overview of current evidence on frailty in ICU settings, a summary of the implementation process, and a demonstration on how to assign CFS scores in eCritical MetaVision $^{T M}$. This included: 1) grand rounds in both major academic sites with video-conference to all zonal and regional ICU sites; 2) online webinars; 3) development of a dedicated CFS implementation website; and 4) a project newsletter.

eCritical analysts built and configured the CFS into eCritical MetaVision $^{T M}$ documentation, followed by creation of mock-ups of the CFS documentation in eCritical development and test systems to allow for improvement cycles, and functional and technical testing before production. The nine-point CFS score appears as a drop-down list coupled with a visual analogue guide and scoring definitions embedded directly into the Physician Admission Form (eFigs 1-5, available as ESM).

The Physician Admission Form is mandatorily completed by the admitting intensivist within the first 24 $\mathrm{hr}$ for every new patient admitted to the ICU. Data captured on this form include demographics, diagnostic, comorbidities, case-mix, and illness acuity data. Once documented by the admitting intensivist in eCritical MetaVision $^{T M}$, the CFS score is further integrated and displayed across inter-professional charting, including nursing, physiotherapy, occupational therapy, dietetics, and social work.

The CFS was implemented in eCritical MetaVision ${ }^{T M}$ as a permanent addition to the Physician Admission Form in December 2015 in all adult ICUs in Alberta. During the initial implementation phase, documentation of the CFS score was made a non-mandatory field on the form in order 
to audit the compliance with documentation and allow for user feedback on usability. A threshold of $\geq 80 \%$ completion of CFS scores was targeted. Compliance data were audited, and ICU-level feedback reports were provided quarterly. The CFS scores were also exported into the eCritical TRACER data repository to enable reporting of aggregate "frailty" reports (eFig. 6, available as ESM). In response to user feedback, the CFS documentation was modified to include the additional choice of "Not sure despite review of available information"; with the intent to transition CFS score documentation to a mandatory data element.

Exposures and outcomes

The primary exposure was the CFS score at the time of ICU admission, ${ }^{5,20}$ and frailty was defined as a CFS score $\geq 5$. The primary outcome was all-cause hospital mortality. Secondary outcomes included ICU mortality, hospital discharge disposition (i.e., home, skilled nursing facility, hospital transfer), measures of organ support (i.e., receipt of mechanical ventilation, vasoactive therapy, and RRT), and health service use (i.e., ICU stay, hospital stay).

\section{Statistical analysis}

Descriptive statistics were stratified according to CFS score $\leq 4$ compared with CFS score $\geq 5$. Nonparametric univariate comparisons were performed to assess the impact of frailty on primary and secondary outcome measures. Normally (and near normally) distributed continuous data were reported as mean (standard deviation $[\mathrm{SD}]$ ) and compared using the Student's t-test. Non-normally distributed continuous data were reported as median [interquartile range (IQR)] and compared using the Mann-Whitney U test. Categorical variables were compared using Likelihood Ratio and Pearson's Chisquared tests for independence. Independent risk factors for hospital mortality and selected organ supports were identified by multivariate logistic regression using CFS score at ICU admission, age, sex, diagnostic category, preICU duration of hospitalization, and APACHE II score as covariates. Results were presented as odds ratios with $95 \%$ confidence intervals (CI). All comparisons were considered statistically significant with a $P$ value $<0.05$. Analyses were performed using Stata 14 (StataCorp, College Station, TX, USA).

\section{Results}

There were 19,556 patients admitted to Alberta ICUs during the study period (Fig. 1). After excluding patients with missing CFS scores $(n=3,669 ; 19 \%)$ (eTables 2-3, available as ESM) and those who died within $24 \mathrm{hr}$ following admission ( $n=649 ; 3 \%)$, a total of $15,238(81 \%)$ patients were included. At the time of data extraction, 122 $(0.8 \%)$ patients remained alive and still in hospital 90 days
Fig. 1 Selection of Alberta ICU patients for the study cohort. ICU $=$ intensive care unit

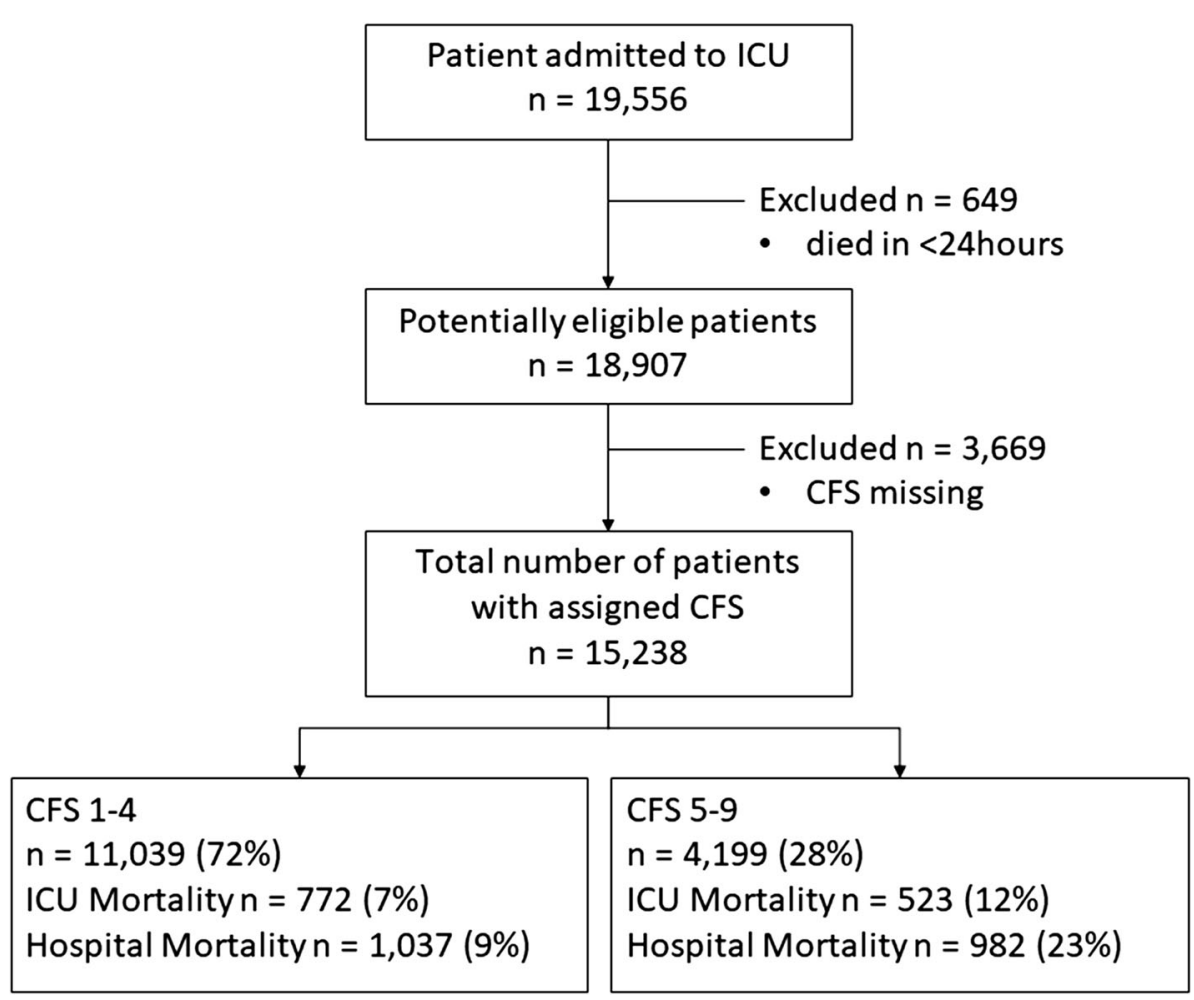


Table 1 Distribution of Clinical Frailty Scale scores across 17 adult ICUs in Alberta

\begin{tabular}{|c|c|c|c|c|}
\hline $\mathrm{ICU}$ & Total $(n=15,238)$ & $\mathrm{CFS} \leq 4$ (Not frail) $(n=11,039 ; 72 \%)$ & $\mathrm{CFS} \geq 5$ (Frail) $(n=4,199 ; 28 \%)$ & $P$ \\
\hline 1. & 699 & $436(62 \%)$ & $263(38 \%)$ & $<0.001$ \\
\hline 2. & 1,645 & $1,504(91 \%)$ & $141(9 \%)$ & $<0.001$ \\
\hline 3. & 1,541 & $1,212(79 \%)$ & $329(21 \%)$ & $<0.001$ \\
\hline 4. & 641 & $507(79 \%)$ & $134(21 \%)$ & $<0.001$ \\
\hline 5. & 1,528 & $983(64 \%)$ & $545(36 \%)$ & $<0.001$ \\
\hline 6. & 422 & $326(77 \%)$ & $96(23 \%)$ & $<0.05$ \\
\hline 7. & 602 & $360(60 \%)$ & $242(40 \%)$ & $<0.001$ \\
\hline 8. & 274 & $240(88 \%)$ & $34(12 \%)$ & $<0.001$ \\
\hline 9. & 927 & $663(72 \%)$ & $264(28 \%)$ & 0.52 \\
\hline 10 & 448 & $358(80 \%)$ & $90(20 \%)$ & $<0.001$ \\
\hline 11. & 1,569 & $1,097(70 \%)$ & $472(30 \%)$ & $<0.05$ \\
\hline 12. & 591 & $405(69 \%)$ & $186(31 \%)$ & $<0.05$ \\
\hline 13. & 582 & $421(72 \%)$ & $161(28 \%)$ & 0.95 \\
\hline 14. & 500 & $284(57 \%)$ & $216(43 \%)$ & $<0.001$ \\
\hline 15. & 461 & $314(68 \%)$ & $147(32 \%)$ & $<0.05$ \\
\hline 16. & 1,917 & $1,202(63 \%)$ & $715(37 \%)$ & $<0.001$ \\
\hline 17. & 891 & $727(82 \%)$ & $164(18 \%)$ & $<0.001$ \\
\hline
\end{tabular}

$\mathrm{ICU}=$ intensive care unit

after ICU discharge. Overall compliance with CFS score completion was $81 \%$ and showed improvement over time (eTable 4, available as ESM).

Overall, the mean (SD) age was $58(17) \mathrm{yr}, 39 \%(n=$ $5,984)$ were female, mean (SD) APACHE II score was 19 (8), and $38 \%(n=5,750)$ were admitted following surgery. ICU and hospital mortality were $9 \%(n=1,295)$ and $13 \%$ $(n=2,019)$, respectively.

Prevalence of frailty in ICU

The median [IQR] CFS score was 3 (2-5). In total, 28\% $(n=4,199)$ had a CFS score $\geq 5$. There were significant differences across ICUs in the proportions of patients with a CFS score $\geq 5$ (range, $9-43 \% ; P<0.001$ ) (Table 1 ; Fig. 2).

\section{Patient characteristics stratified by CFS score}

The CFS scores were higher in older patients (Fig. 3; Table 2). Patients with CFS score $\geq 5$ were significantly older compared with those with CFS score $\leq 4$ [mean (SD) 63 (15) yr vs 56 (17) yr; $P<0.001)$. Females had higher CFS scores compared with males (median [IQR] $4{ }^{2-5}$ vs 3 $\left.{ }^{2-4} ; P<0.001\right)$, and the proportion of CFS scores $\geq 5$ was higher in females than males ( $32 \%$ of females vs $25 \%$ of males; $P<0.001$ ).

The CFS scores were lower in patients admitted for surgical compared with medical diagnoses $\left(3^{3,4} v s 4^{2-5} ; P\right.$
$<0.001)$. Patients with a CFS score $\geq 5$ were more likely non-operative (medical) compared with those with a CFS score $\leq 4(69 \%$ vs $57 \% ; P<0.001)$. APACHE II scores at admission were correlated with CFS score (Fig. 4). Patients with CFS score $\geq 5$ had higher mean (SD) APACHE II scores [22 (8) vs 17 (8); $P<0.001]$ and admission SOFA scores [7 (4) vs 6 (4); $P<0.001]$ compared with those with a CFS score $\leq 4$ (Table 2).

Patient outcomes and health service use

In multivariable analysis, ICU death was not statistically different for patients with CFS scores $\geq 5$ compared with those with CFS scores $\leq 4(12 \%$ vs $7 \%$; adjusted odds ratio [OR], $1.09 ; 95 \% \mathrm{CI}, 0.95$ to $1.25 ; P=0.21$ ). Hospital death was greater for patients with CFS scores $\geq 5$ compared with CFS scores $\leq 4$ (23\% vs 9\%; adjusted OR, 1.83 ; 95\% CI, 1.64 to $2.05 ; P<0.001$ ) (Table 3 ). In analysis using the CFS score as a continuous variable, a higher CFS score was associated with greater hospital mortality (adjusted OR, $1.19 ; 95 \% \mathrm{CI}, 1.15$ to $1.23 ; P<0.001)$, and showed further gradient increases for CFS scores $>5$ (eTable 5 , available as ESM).

Patients with CFS score $\geq 5$ were less likely to receive invasive mechanical ventilation $(62 \%$ vs $68 \%$; adjusted OR, $0.56 ; 95 \%$ CI, 0.51 to $0.61 ; P<0.001)$ but were more likely to receive non-invasive ventilation (22\% vs $9 \%$; adjusted OR, 2.07; 95\% CI, 1.86 to $2.31 ; P<0.001$ ) compared with patients with CFS score $\leq 4$ (Table 2). 


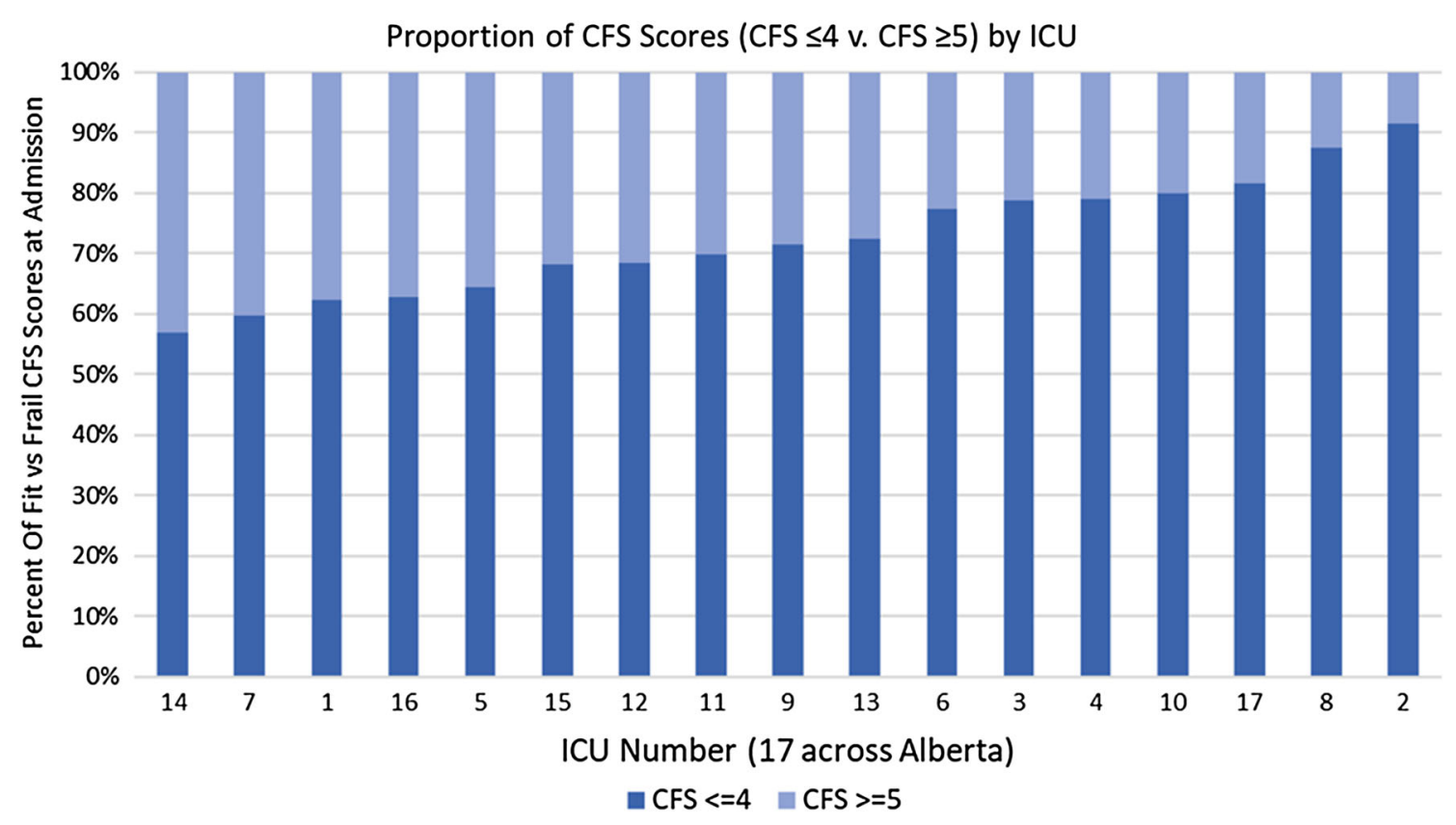

Fig. 2 Distribution of CFS scores among 17 adult ICUs in Alberta. CFS = Clinical Frailty Scale; ICU = intensive care unit

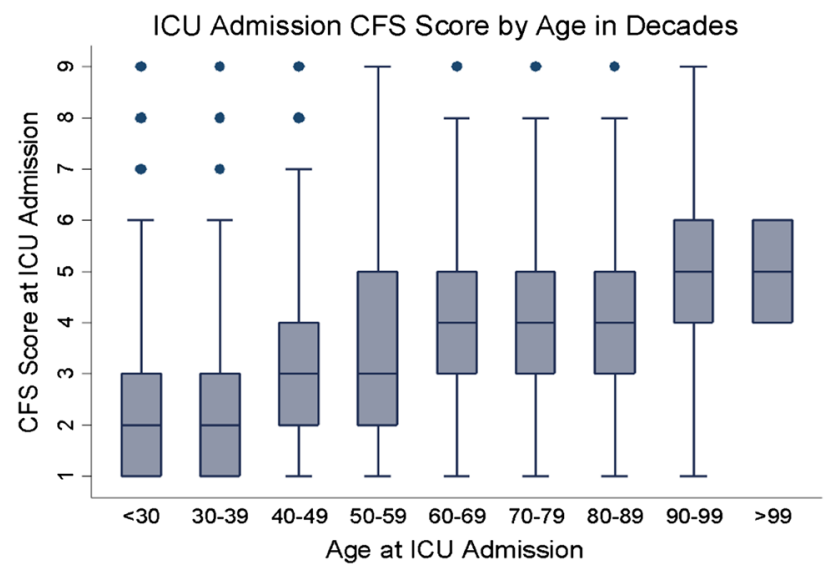

Fig. 3 Distribution of CFS scores by age group among patients admitted to 17 adult ICUs in Alberta. CFS = Clinical Frailty Scale; $\mathrm{ICU}=$ intensive care unit

Patients with CFS score $\geq 5$ were also less likely to receive vasoactive support (24\% vs 57\%; adjusted OR, 0.73; $95 \%$ CI, 0.67 to $0.80 ; P<0.001)$, though use of RRT was similar (7\% vs 5\%; adjusted OR, 0.95; $95 \%$ CI, 0.80 to $1.13 ; P=0.60)$ compared with those with CFS score $\leq 4$. Among patients receiving any form of organ support, those with CFS score $\geq 5$ received it for longer durations that patients with CFS score $\leq 4$ (Table 2).

Patients with CFS score $\geq 5$ had longer median [IQR] ICU stay (4 [2.1-8.0] vs 3 [1.5-5.9] days; $P<0.001)$ and total hospital stay (16 [7.6-36.0] vs 10 [5.2-20.3] days; $P<$ 0.001 ) compared with those with a CFS score $\leq 4$. Patients with CFS score $\geq 5$ also had longer median [IQR] hospital stay prior to ICU admission (0.4 [0.02-4.7] vs $0.2[0.01-$ 1.3] days; $P<0.001)$ and after ICU discharge (7 [0.7-19.0] vs 4 [0.9-10.7] days; $P<0.001)$ (Table 3).

Discharge disposition

The majority (79\%) of patients were discharged from the ICU to an acute care unit or another acute care facility, with the next most common disposition being discharge home (9\%) or deceased in ICU (9\%). Patients with CFS score $\leq 4$ were more likely to be discharged directly home compared with those with CFS score $\geq 5(11 \%$ vs $6 \% ; P<$ 0.001) (Table 4).

\section{Discussion}

National guidelines have recommended population-level screening for frailty. ${ }^{13,21}$ Aligned with this recommendation, we have successfully implemented a validated frailty measure, the CFS score, into our provincial ICU-specific EHR, which is routinely completed by attending ICU physicians for all adult ICU admissions in Alberta. We have shown that populationlevel screening for frailty in ICU settings is feasible.

Context with prior work

In this first population-level description of frailty screening in ICU settings, we confirmed prior data showing that frailty, captured by the CFS score, was common, occurring 
Table 2 Summary of patient characteristics stratified by Clinical Frailty Scale score

\begin{tabular}{|c|c|c|c|c|}
\hline Feature & Total $(n=15,238)$ & $\mathrm{CFS} \leq 4($ Not frail $)(n=11,039 ; 72 \%)$ & $\mathrm{CFS} \geq 5$ (Frail) $(n=4,199 ; 28 \%)$ & $P$ \\
\hline Age $(y r)$, mean $(S D)$ & $58(17)$ & $56(17)$ & $63(15)$ & $<0.001$ \\
\hline Sex (female), $n(\%)$ & $5,984(39)$ & $4,067(37)$ & $1,917(46)$ & $<0.001$ \\
\hline Admission category, $n(\%)$ & & & & $<0.001$ \\
\hline Medical/non-operative & $9,184(60)$ & $6,274(57)$ & $2,910(69)$ & \\
\hline Elective surgical & $3,447(23)$ & $2,821(26)$ & $626(15)$ & \\
\hline Emergency surgical & $2,524(17)$ & $1,896(17)$ & $628(15)$ & \\
\hline No admission category assigned & $83(0.5)$ & $48(0.4)$ & $35(0.8)$ & \\
\hline Admission classification, $n(\%)$ & & & & $<0.001$ \\
\hline Medical & $7,506(49)$ & $4,968(45)$ & $2,538(60)$ & \\
\hline Neurology & $1,188(8)$ & $956(9)$ & $232(6)$ & \\
\hline Surgical & $5,750(38)$ & $4,440(40)$ & $1,310(31)$ & \\
\hline Trauma & $700(5)$ & $620(6)$ & $80(2)$ & \\
\hline No admission classification assigned & $94(0.6)$ & $55(0.5)$ & $39(0.9)$ & \\
\hline Diagnostic category, $n(\%)$ & & & & $<0.001$ \\
\hline Cardiovascular & $4,768(31)$ & $3,602(33)$ & $1,166(28)$ & \\
\hline Respiratory & $2,165(20)$ & $1,322(31)$ & $3,487(23)$ & \\
\hline Gastrointestinal/hepatic & $1,757(12)$ & $1,197(11)$ & $560(13)$ & \\
\hline Endocrine/metabolic & $434(3)$ & $363(3)$ & $71(2)$ & \\
\hline Neurologic & $2,536(17)$ & $2,036(18)$ & $500(12)$ & \\
\hline Hematologic/oncologic & $39(0.3)$ & $24(0.2)$ & $15(0.4)$ & \\
\hline Musculoskeletal & $442(3)$ & $295(3)$ & $147(4)$ & \\
\hline Urological/kidney & $432(3)$ & $301(3)$ & $131(3)$ & \\
\hline Trauma & $886(6)$ & $769(7)$ & $117(3)$ & \\
\hline Transplant & $218(1)$ & $106(1)$ & $112(3)$ & \\
\hline No diagnostic category assigned & $239(2)$ & $181(2)$ & $58(1)$ & \\
\hline APACHE II score, mean (SD) & $19(8)$ & $17(8)$ & $22(8)$ & $<0.001$ \\
\hline Admission SOFA score, mean (SD) & $6(4)$ & $6(4)$ & $7(4)$ & $<0.001$ \\
\hline Invasive mechanical ventilation, $n(\%)$ & $10,124(66)$ & $7,527(68)$ & $2,597(62)$ & $<0.001$ \\
\hline Duration (days), median [IQR] & $1[0.4-3.9]$ & $1[0.3-3.5]$ & $2[0.7-5.2]$ & $<0.001$ \\
\hline Non-invasive ventilation, $n(\%)$ & $1,894(12)$ & $957(9)$ & $937(22)$ & $<0.001$ \\
\hline Duration (days), median [IQR] & $0.9[0.3-2.3]$ & $0.7[0.3-1.9]$ & $1[0.3-2.5]$ & $<0.001$ \\
\hline Vasoactive medications, $n(\%)$ & $7,743(51)$ & $5,494(57)$ & $2,249(24)$ & $<0.001$ \\
\hline Duration (days), median [IQR] & $1[0.3-3.2]$ & $1[0.3-2.8]$ & $2[0.5-4.1]$ & $<0.001$ \\
\hline Renal replacement therapy, $n(\%)$ & $803(5)$ & $496(5)$ & $307(7)$ & $<0.001$ \\
\hline Duration (days), median [IQR] & $3.2[1.6-6.8]$ & $3[1.5-6.8]$ & $4[1.7-7.1]$ & 0.308 \\
\hline
\end{tabular}

APACHE = Acute Physiology and Chronic Health Evaluation; IQR = interquartile range; SD = standard deviation; SOFA = Sequential Organ Failure Assessment

in one in four admissions. ${ }^{5-7}$ We also found considerable variation in reported frailty prevalence across adult ICUs in Alberta. Frailty prevalence was modified by several factors, particularly age, sex, case-mix, surgical status, and illness acuity. Prior work is limited because it only describes frailty in older ICU cohorts (i.e., $\geq 65$, $\geq 80 \mathrm{yr}$ ); however, our study adds new knowledge by evaluating frailty at a population-level across an adult age continuum. ${ }^{8,22-24}$ The average age of frail patients in our cohort was only $63 \mathrm{yr}$, suggesting a significant number of younger persons living with frailty may be at substantial risk for critical illness and associated adverse outcomes. ${ }^{10}$ Baseline frailty status was found to confer greater risk of hospital death, as well as longer duration of post-ICU and total hospitalization. These data further support prior work establishing the predictive validity of the CFS and association with patient outcomes. ${ }^{5,6,23}$ Frailty status was also associated with differences in health service use and advanced organ support. Fewer frail patients were treated with invasive mechanical ventilation and vasoactive 


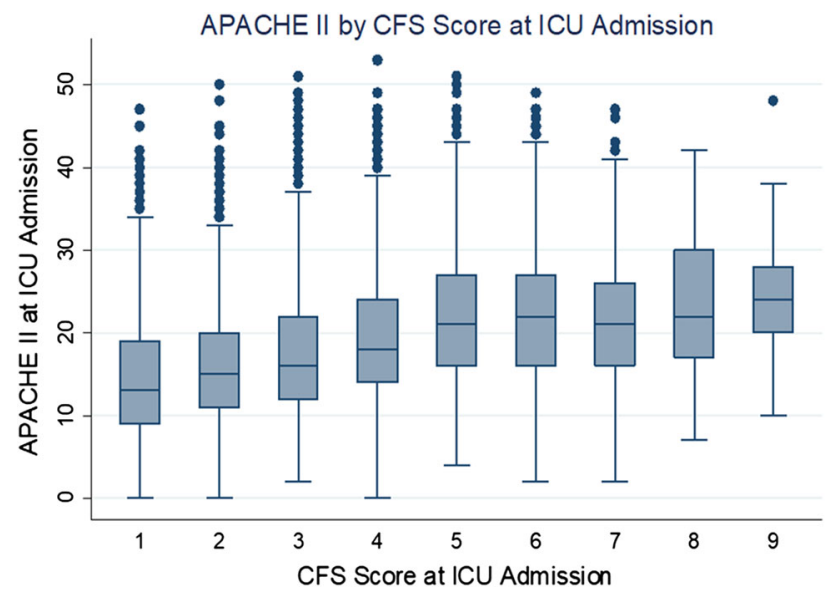

Fig. 4 Distribution of admission APACHE II scores across CFS scores among patients admitted to 17 adult ICUs in Alberta. APACHE = Acute Physiology and Chronic Health Evaluation; CFS $=$ Clinical Frailty Scale; ICU = intensive care unit support; while more received non-invasive ventilation compared with non-frail patients. ${ }^{8}$

Implications for clinicians, policy, and research

Provincial-level screening for frailty upon ICU admission provides novel information on its prevalence and evolving burden. ${ }^{13,21}$ Variations in reported prevalence across ICUs can provide insights into where enhanced evaluation and/or support structures can be targeted. Routine frailty evaluation, as shown in our study, also provides opportunity for healthcare decision-makers to better strategically plan for future health service demand. A growing prevalence of patients living with frailty and developing critical illness with organ support in ICU settings should factor into resource and capacity planning for ICU services, particularly recognizing their greater

Table 3 Summary of patient outcomes stratified by CFS score

\begin{tabular}{|c|c|c|c|c|}
\hline Feature & $\begin{array}{l}\text { Total } \\
(n=15,238)\end{array}$ & $\begin{array}{l}\text { CFS } \leq 4 \\
\text { (Not frail) } \\
(n=11,039 ; 72 \%)\end{array}$ & $\begin{array}{l}\mathrm{CFS} \geq 5 \\
\text { (Frail) } \\
(n=4,199 ; 28 \%)\end{array}$ & $P$ \\
\hline ICU death, $n(\%)$ & $1,295(9)$ & $772(7)$ & $523(12)$ & $<0.001$ \\
\hline Hospital death, $n(\%)$ & $2,019(13)$ & $1,037(9)$ & $982(23)$ & $<0.001$ \\
\hline ICU LOS (days), median [IQR] & $3.0[1.7-6.4]$ & $3.0[1.5-5.9]$ & $4.0[2.1-8.0]$ & $<0.001$ \\
\hline Hospital LOS (days), median [IQR] & $11.0[5.7-23.8]$ & $10.0[5.2-20.3]$ & $16.0[7.6-36.0]$ & $<0.001$ \\
\hline Hospital stay prior to ICU admission (days), median [IQR] & $0.3[0.01-1.9]$ & $0.2[0.01-1.3]$ & $0.4[0.02-4.7]$ & $<0.001$ \\
\hline Hospital stay following ICU discharge (days), median [IQR] & $5[0.9-12.7]$ & $4[0.9-10.7]$ & $7[0.7-19.0]$ & $<0.001$ \\
\hline
\end{tabular}

CFS = Clinical Frailty Scale; ICU = intensive care unit; IQR = interquartile range; LOS = length of stay

Table 4 Summary of ICU discharge destination stratified by CFS score

\begin{tabular}{llllr}
\hline ICU discharge destination & Total $(n=15,238)$ & $\begin{array}{l}\text { CFS } \leq 4 \text { (Not frail) } \\
(n=11,039 ; 72 \%)\end{array}$ & CFS $\geq 5$ (Frail) $(n=4,199 ; 28 \%)$ & $P$ \\
\hline Acute ward or hospital & $12,060(79 \%)$ & $8,777(80 \%)$ & $3,283(78 \%)$ & 0.07 \\
Deceased & $1,295(9 \%)$ & $772(7 \%)$ & $523(12 \%)$ & $<0.001$ \\
Home & $1,392(9 \%)$ & $1,160(11 \%)$ & $65(2 \%)$ & $<0.001$ \\
Transfer to alterative ICU/CCU & $200(1 \%)$ & $135(1 \%)$ & $23(0.6 \%)$ & $3(0.07 \%)$ \\
Long-term care & $27(0.2 \%)$ & $4(0.04 \%)$ & $1(0.02 \%)$ & $<0.12$ \\
Hospice & $4(0.03 \%)$ & $1(0.01 \%)$ & $0(0 \%)$ & 0.05 \\
Detox & $3(0.02 \%)$ & $2(0.02 \%)$ & $69(2 \%)$ & 0.82 \\
Sub-acute or rehabilitation & $2(0.01 \%)$ & $2(0.02 \%)$ & 0.38 \\
Not documented & $255(2 \%)$ & $186(2 \%)$ & 0.86
\end{tabular}

CFS = Clinical Frailty Scale; CCU = critical care unit; ICU = intensive care unit 
complexity, their longer recovery, and their greater health service use. ${ }^{5,6}$

Identifying vulnerable and frail patients upon ICU admission presents unique opportunities for the design and implementation of health service innovations aimed at improving the quality and transitions in care for those surviving their acute episode of critical illness. ${ }^{25}$ Such interventions could include interdisciplinary ICU care pathways to personalize recovery and transitions of care. Including the CFS in ICU care pathways could trigger confirmatory evaluations and detailed interrogation of frailty domains (i.e., multidimensional frailty measures or a comprehensive geriatric assessment), as well as timely referral to clinicians with expertise in frailty-specific interventions (e.g., geriatric medicine, dietetics, rehabilitative medicine, palliative care). Interventions and focused care pathways targeting prevention or mitigation of disability onset or worsening severity in ICU could align with frailty case-finding to better identify patients most likely to benefit, and improve functional outcomes post ICU. 6,22

The relationship between baseline frailty status prior to critical illness and new or worsening functional and cognitive disability among survivors is well established $^{12,26,27}$; however, future work should further aim to unravel whether there is an association between baseline frailty, the development of chronic or persistent critical illness, and trajectories in survivorship amenable to care innovation to improve outcomes of ICU stay, as well as subsequent hospital stay. ${ }^{16}$ This may also include opportunities for frail survivors of critical illness to revisit goals-of-care discussions with family and healthcare professionals. There are also little data focused on how clinicians may use information about frailty status in their discussions with patients and families or to guide decisionmaking prior to admission or during their course in ICU. In the VIP study, older frail patients were significantly more likely to have support withheld and withdrawn in the ICU compared with non-frail patients. ${ }^{8}$

\section{Strengths and limitations}

Our study is notable for provincial population-level ascertainment of all ICU admissions; having the CFS score routinely documented by the most responsible physician (i.e., attending ICU physician); and having robust and comprehensive clinical, outcome, and health services data to associate with measures of frailty. We also showed improved compliance with CFS completion over the duration of the study, implying greater adoption by ICU physicians. Nevertheless, our study has important limitations. First, a significant proportion of CFS scores were missing. This was because completion of the CFS score in the Physician Admission Form was not mandatory. We have shown with education, audit and feedback, and reminders, that completing the CFS significantly improved during the study. Second, because CFS scores were obtained after ICU admission, we are unable to comment whether frailty was an important determinant for decisions not to admit patients (i.e., patients who declined or were not offered ICU admission). Both of these may contribute to selection and information bias, inherent in all observational studies. Third, we recognize the CFS was initially validated in ambulatory care settings to screen for frailty and, while also showing predictive validity in ICU settings, we did not confirm frailty status with a more comprehensive evaluation (i.e., multidimensional or comprehensive geriatric assessment). Similarly, we were also not able to evaluate the inter-rater reliability of CFS score assignment. Fourth, we did not have data on patient goals-of-care status at ICU admission, whether this changed during ICU admission, or other decisions related to the intensity or duration of ICU support. Fifth, we did not have data on long-term outcomes beyond index hospitalization, though prior data have shown frailty to be associated with greater mortality and institutionalization, and impaired quality-of-life. ${ }^{6,22,27}$ Finally, while this is a provincial population-level study, it is limited to a single Canadian province and may not be generalizable to other health jurisdictions.

\section{Conclusion}

It was feasible to implement a validated measure of frailty at the population-level into a provincial ICU-specific EHR. Frailty was common, occurring in one in four adults admitted to the ICU, and was associated with a disproportionate risk of hospital death. Frail patients showed important differences in organ support and health service use that may have prognostic and health planning implications. The value of this novel method of frailty screening can meaningfully support appropriate frailtyspecific ICU interventions and future healthcare resource planning.

Acknowledgements We would like to acknowledge the vital contributions of the eCritical Alberta team for the development, testing, optimization, and reporting of the CFS within eCritical systems, in particular Malik Agyemang, Jo Harris, Dan Jones, Eric Esau, Cathy Curr, Faith Ko, and Jocelyn Anderson.

Disclosures Carmel Montgomery is a 2017 CFN Interdisciplinary Fellow. Dr. Bagshaw holds a Canada Research Chair in Critical Care Nephrology. Dr. Stelfox is supported by CIHR Embedded Clinician Researcher Award.

Conflicts of interest None declared. 
Editorial responsibility This submission was handled by Dr. Sangeeta Mehta, Associate Editor, Canadian Journal of Anesthesia.

Author contributions Carmel L. Montgomery and Sean M. Bagshaw contributed to all aspects of this manuscript, including study conception and design; acquisition, analysis, and interpretation of data; and drafting the article. Carmel L. Montgomery, Henry T. Stelfox, and Sean M. Bagshaw contributed to the study conception and design of the manuscript. Carmel L. Montgomery, Danny J. Zuege, Darren Hudson, Henry T. Stelfox, and Sean M. Bagshaw contributed to the acquisition of data. Carmel L. Montgomery and Sean M. Bagshaw contributed to the analysis of data. Carmel L. Montgomery, Danny J. Zuege, Darryl B. Rolfson, Dawn Opgenorth, Darren Hudson, Henry T. Stelfox, and Sean M. Bagshaw contributed to the interpretation of data.

Sources of funding This work was supported by the Canadian Frailty Network (FRA2015-B-20). This work was performed at the University of Alberta and the University of Calgary.

\section{References}

1. Gill TM, Allore HG, Gahbauer EA, Murphy TEl. Change in disability after hospitalization or restricted activity in older persons. JAMA 2010; 304: 1919-28.

2. Gill TM, Allore HG, Holford TR, Guo Z. Hospitalization, restricted activity, and the development of disability among older persons. JAMA 2004; 292: 2115-24.

3. Gill TM, Gahbauer EA, Han L, Allore HG. Trajectories of disability in the last year of life. N Engl J Med 2010; 362: 117380.

4. Herridge MS, Chu LM, Matte A, et al. The RECOVER Program: disability risk groups and 1-year outcome after 7 or more days of mechanical ventilation. Am J Respir Crit Care Med 2016; 194 : 831-44.

5. Bagshaw SM, Stelfox HT, McDermid RC, et al. Association between frailty and short- and long-term outcomes among critically ill patients: a multicentre prospective cohort study. CMAJ 2014; 186: E95-102.

6. Brummel NE, Bell SP, Girard TD, et al. Frailty and subsequent disability and mortality among patients with critical illness. Am J Respir Crit Care Med 2017; 196: 64-72.

7. Zampieri FG, Iwashyna TJ, Viglianti EM, et al. Association of frailty with short-term outcomes, organ support and resource use in critically ill patients. Intensive Care Med 2018; 44: 1512-20.

8. Flaatten $H$, De Lange DW, Morandi A, et al. The impact of frailty on ICU and 30-day mortality and the level of care in very elderly patients ( $\geq 80$ years). Intensive Care Med 2017; 43: 1820-8.

9. Muessig JM, Nia AM, Masyuk M, et al. Clinical Frailty Scale (CFS) reliably stratifies octogenarians in German ICUs: a multicentre prospective cohort study. BMC Geriatr 2018; 18 : 162.

10. Bagshaw M, Majumdar SR, Rolfson DB, Ibrahim Q, McDermid $R C$, Stelfox $H T$. A prospective multicenter cohort study of frailty in younger critically ill patients. Crit Care 2016; 20: 175.

11. Muscedere J, Waters B, Varambally A, et al. The impact of frailty on intensive care unit outcomes: a systematic review and metaanalysis. Intensive Care Med 2017; 43: 1105-22.
12. Montgomery $C L$, Rolfson DB, Bagshaw SM. Frailty and the association between long-term recovery after intensive care unit admission. Crit Care Clin 2018; 34: 527-47.

13. Rolfson DB, Heckman GA, Bagshaw SM, Robertson D, Hirdes $J P$. Implementing Frailty measures in the Canadian healthcare system. J Frailty Aging 2018; 7: 208-16.

14. Brundin-Mather R, Soo A, Zuege DJ, et al. Secondary EMR data for quality improvement and research: a comparison of manual and electronic data collection from an integrated critical care electronic medical record system. J Crit Care 2018; 47: 295-301.

15. von Elm E, Altman DG, Egger M, et al. The Strengthening the Reporting of Observational Studies in Epidemiology (STROBE) statement: guidelines for reporting observational studies. Lancet 2007; 370: 1453-7.

16. Bagshaw SM, Stelfox HT, Iwashyna TJ, Bellomo R, Zuege D, Wang $X$. Timing of onset of persistent critical illness: a multicentre retrospective cohort study. Intensive Care Med 2018; 44: 2134-44.

17. Bagshaw SM, Wang X, Zygun DA, et al. Association between strained capacity and mortality among patients admitted to intensive care: a path-analysis modeling strategy. J Crit Care 2018; 43: 81-7.

18. Stelfox HT, Hemmelgarn BR, Bagshaw SM, et al. Intensive care unit bed availability and outcomes for hospitalized patients with sudden clinical deterioration. Arch Intern Med 2012; 172: 46774.

19. Stelfox HT, Soo A, Niven DJ, et al. Assessment of the safety of discharging select patients directly home from the intensive care unit: a multicenter population-based cohort study. JAMA Intern Med 2018; 178: 1390-9.

20. Rockwood K, Song X, MacKnight C, et al. A global clinical measure of fitness and frailty in elderly people. CMAJ 2005; 173: 489-95.

21. Muscedere J, Andrew MK, Bagshaw SM, et al. Screening for frailty in Canada's health care system: a time for action. Can J Aging 2016; 35: 281-97.

22. Ferrante LE, Pisani MA, Murphy TE, Gahbauer EA, LeoSummers LS, Gill TM. The association of frailty with post-ICU disability, nursing home admission, and mortality: a longitudinal study. Chest 2018; 153: 1378-86.

23. Le Maguet P, Roquilly A, Lasocki S, et al. Prevalence and impact of frailty on mortality in elderly ICU patients: a prospective, multicenter, observational study. Intensive Care Med 2014; 40: 674-82.

24. Hope AA, Gong MN, Guerra C, Wunsch H. Frailty before critical illness and mortality for elderly Medicare beneficiaries. J Am Geriatr Soc 2015; 63: 1121-8.

25. Stelfox $H T$, Lane D, Boyd JM, et al. A scoping review of patient discharge from intensive care: opportunities and tools to improve care. Chest 2015; 147: 317-27.

26. Ehlenbach WJ, Hough CL, Crane PK, et al. Association between acute care and critical illness hospitalization and cognitive function in older adults. JAMA 2010; 303: 763-70.

27. Bagshaw SM, Stelfox HT, Johnson JA, et al. Long-term association between frailty and health-related quality of life among survivors of critical illness: a prospective multicenter cohort study. Crit Care Med 2015; 43: 973-82.

Publisher's Note Springer Nature remains neutral with regard to jurisdictional claims in published maps and institutional affiliations. 